\title{
Research on the Influence of Industrial Images on Painting
}

\author{
Renjie Zhang ${ }^{1, *}$ \\ ${ }^{1}$ College of Art and Design, Wuhan Textile University, Wuhan, Hubei 430073, China \\ *Corresponding author. Email: 1874045716@qq.com
}

\begin{abstract}
Contemporary art trends of thought and the pluralistic development of expression have blurred the boundary of art. Painting art is no exception. In terms of presentation mode and evolution process, there are many relations between painting art and industrial image. From the development process of industrial images and the influence of industrial images on painting art, this paper expounds the relationship between painting art and industrial images, and proposes that the independence of painting art should be maintained at present.
\end{abstract}

Keywords: industrial image, painting art, influence, relationship

\section{INTRODUCTION}

The progress of society, the development of science and technology and the change of people's aesthetic concept have posed new opportunities and challenges to the development of traditional art. Gombrich, a famous English art theorist, once said that the whole history of art is not the history of technical proficiency, but the history of the change of ideas and requirements. In the long history of art creation, industrial images and painting art interact and influence each other. Combining years of research on easel painting, Chen Danqing pointed out that the history of Western modern art is the history of the conflict between painting and image painting. [1]

\section{INDUSTRIAL IMAGE}

What is an image? It can be considered a man-made visual product. The image itself does not include threedimensional products, and the image is mainly flat. It ranges widely. In addition to the familiar traditional images such as oil painting, ink painting and printmaking, photography, television, digital images and commercial advertisements in contemporary society are all included in the category of images. Their production is inseparable from the scientific and technological achievements of modern industrial civilization, so they are called industrial images. Before the 19th century, the production and manufacture of images were still in a very primitive stage. Such as church murals, book illustrations, hotel signs and so on. Such image appears in the form of hand with limited transmission ability. The most effective way of dissemination then was printmaking, which could be copied in batches. This played an extremely important role in the spread of culture, indoctrination and beautification of life. With the realization of various social functions, the art of painting has also developed rapidly. In this process, the artist has made great progress in the exploration of reproducing nature in such aspects as modeling ability, composition ability and the ability to understand nature. The progress that man has made in the face of nature has not stopped him from longing for the lifelike reproduction of nature. Man has an instinctive desire to reproduce nature realistically. Thanks to the efforts of generations of visual workers and the development of science and technology, the invention of photography technology in the middle of the 19th century can be said to realize the dream of mass production of realistic images, which opened the prelude to the development of industrial images. Industrial images have led to a revolution in the way image information is transmitted. It is far superior to traditional manual images in authenticity, accuracy, reproducibility and transmissibility.

The development of photographic technology, the invention of portable cameras and rapid lithography allowed the proliferation of portraits and landscape photographs. This function, originally carried by painting, has been increasingly replaced by photography. People no longer record and depict human feelings and styles only through painting. Photography technology is popular with the public for its convenience. Some people who do not care the art of painting join the camp of photography. With the rise of mass culture, industrial images began to interfere in people's lives, squeezing traditional painting out of the mainstream of visual art. The development of industry and the rise of cities prompted some farmers to move into cities. In the urban environment, their cultural knowledge has been improved and their amateur 
cultural needs have increased, and a mass culture has emerged for this large group. Then came colorful popular paintings, commercial literature and art, magazine covers, illustrations, advertisements, films and television. Many are related to industrial images and are presented to the public in the form of industrial images. At the same time, painting returned to its own form after various changes. Some painters show people the unique expressiveness of color, shape and form of their works through their own artistic practices. All elements of visual art, such as lines, colors and forms, have an expression independent of the world, and their vitality is rooted in the self-restraint psychology of human nature. These elements are not chosen by convention for utilitarian or other reasons, as is the case with language and form. They are just abstract symbols that remind human that they are a rich world in their own right. [2] Van Gogh expressed his subjective feelings with strong colors and twisted brushstrokes. Cezanne, in order to obtain the stable picture structure and the solid sense of the substance in nature, constructed the image in nature by "sphere, cylinder and cone". This idea was borrowed by later cubists. Abstractism and minimalism are also unique forms and features that emerge after painting returns to its own form. Image is no longer the leading role of painting art, and painting works are more regarded as creations rather than imitators, thus creating a distance between painting images and industrial images.

\section{Painting}

The form of painting art has become more pure, but in fact the exploration and evolution of painting art has not been recognized and approved by the public. To some extent, the distance between the public and the art of painting has been widened. In modern society, industrial images occupy people's visual space. Color photos, TV, movies and advertisements, with their bright colors, simple images, clear symbols and single image repetition, change people's visual space and appear before people's eyes at any moment. At the same time, paintings are displayed in art galleries, while the general public rarely makes the trip for appreciation. The development of painting art, to some extent, makes painting art an elegant art that requires education and training to be appreciated. Painting art has become a kind of circle culture, and artists' creation has become an individual labor aimed at a certain part of the audience. This makes the modern painting art become the upper class culture, elite culture and art that does not have to be accepted and appreciated by the public. It maintains its development in the art market with its upper class and elite status. In this process, painting art is increasingly marginalized in visual images. The impact of media art and photography art aggravates the tendency of rigidity of realistic painting. Lyricism has never been more important. The borrowing and copying of photos also make contemporary realistic oil painting in deep trouble: convenience and material fixation as well as simple reading of an image. After all, there are many differences between the human eye and the camera, and it is absurd that many people ignore this point. What you see on the spot is definitely different from what you see on the camera. Lyricism seems to be the most important factor that distinguishes painting from photography. Lyricism can directly express the visual feelings of the painter, and also enable the painter to realize the change from simply depicting the reality to freely reading the reality. The reprocessing of natural scenes in Chinese painting can depend on the special language expression of ink painting, and the expressiveness must be strengthened. Detailed feature painting is not only dependent, but should be a kind of consciousness endowed by people subjectively. Thick lines, thin lines, deep lines, shallow lines, and long lines can all express subjective interpretations of reality. The processing of the material in oil painting, the selection of painting style from photos to paintings is bound to be expressive. The photos themselves are limited in size, and the details are blurred. When zoomed in on the canvas, there are no specific details to support the modeling, and the painting process must be accompanied by a certain amount of personal imagination.

Since the 1990s, the rapid development of computers, video cameras, CDS, digital technology and Internet networks has made it inevitable for everyone to be surrounded by industrial images. People, including artists, were deeply influenced by it and the obvious distinction between industrial and painting images disappeared in the middle and late 20th century. The state of mutual interweaving and mutual learning is presented. With the help of painting, photographers sometimes make use of people's cultural identification with traditional and classic paintings to form their own works. The composition, the setting, the movement posture design borrows the traditional painting art. The Japanese photographer Taichang Morimura tampered with the famous 19th-century French painter Miller's "Evening Bell" to intervene in the Western tradition as an Oriental, forcing people to experience the classic works from a new perspective. [3]

\section{THE USE OF IMAGES IN PAINTING}

More commonly, artists use photographs to complete their paintings. After the appearance of industrial images in the form of photographs, many artists began to use photographs to study movements and shapes from particular angles. Delacroix compiled a book of photographs of the human body, while Degas used continuous snapshots of galloping horses taken by Aimee Moro to make himself more accurate in grasping objects. In the process of using industrial images for creation, artists do not simply copy industrial images, 
but use and modify photos, which is not directly related to traditional realistic painting. He uses industrial images, which are realistic and reflect real life. A view of reality expressed through recognizable images. The American painters Andy Warhol's Elvis and Marilyn Monroe superficially only used industrial images, but in fact they profoundly showed the contemporary reality of the United States, the control of the media over people and the influence of mass culture.

Both artists and the public share the same visual experience, which must be reflected in their artistic creation. The conditions they present in their works are closely related to the environment and personal experience of the times in which they lived. Painters in the 1960s experienced a drastic change in society, resulting in their psychologically complexity. This includes the lofty idealism complex, the loss of faith, the desire for instant enjoyment, and the value of the two ages, as well as their hypocrisy and lack. This mindset often puts them in a critical position to use industrial imagery. Wang Guangyi put together the consumption and political elements in industrial images to eliminate political idealism. Zhang Xiaogang used brushstrokes and copied "old photos" to express a nostalgic emotion without passion. Shi Chong adopted images as the carrier of ideas and the representation of intention patterns to bridge the transition between spiritual entities and visible images, so as to complete the preliminary work of creation. [4] The cultural psychological contradiction of people born around the 1970 s is not too obvious, and there is no strong ideological critical consciousness. They resorted a more "gamification" attitude towards the world and life, which is neither exciting nor dull, nor exclusive nor cheering. They connect the ready-made industrial images with their vivid sense of personal life, and use the images to imply a certain psychology so as to express the most sensitive part of the inner world. Therefore, some young painters went into the interior of industrial images and were interested in the production methods of industrial images. Their imitation of the image processing effect of electronic technology was a case in point, aiming at the imitation of current image technologies. The work reminds people of the images seen on other mass media (Internet, film and television, street advertising). Yin Zhaoyang's works hide the texture and interest of oil painting materials by means of "technicalization", and show a kind of cruelty, coolness and indifference by using industrial printing colors. Jiang Heng and Zhong Biao improved the popular images, assembled the simple and bright colors of the advertisement screens, and borrowed the technique of "copying" to directly present the psychological state of "fashionable beauties" in popular culture. Fu Hong's work embodies the "technical" narrative characteristics of the camera by depicting night scene photos. These artists combine their own ideas to process and create different forms of industrial images.

\section{CONCLUSION}

The role of industrial images in art and life is becoming more and more powerful. Nowadays, when industrial images are widely used in art, it is difficult to distinguish images of art from images of life and society. The former tends to be overwhelmed by the latter, and gradually loses the transcendental qualities given by the classics. Industrial images have become the public discourse of modern society, and have increasingly become the language form of modern art. [5] However, it should be seen that the most important thing in the creation of a work of art is not the tools or materials but the artist's thoughts and ideas. The expression of such ideas and artistic concepts can be carried out through a variety of tools or materials. Thus it can be seen that the problem faced by the contemporary development of painting art is not technology or materials, but the lack of artistic concepts and the superficial understanding of contemporary culture The art of painting advances with various new things in the course of history. Where it is headed remains to be seen. One thing to remember is that the art of painting is always an indispensable part of human life and culture.

\section{References}

[1] Evaluation and reflection, a Chinese oil painting creation. Summary of the Seminar [J]. Chinese Oil Painting. 2004: 24. (in Chinese)

[2] Collection of Western Paintings [M]. Jiangsu Fine Arts Publishing House, page 590. (in Chinese)

[3] Photography and Painting Art [J]. Journal of Nanjing Art Institute, Art and Design, page 50. (in Chinese)

[4] Case Study of Famous Contemporary Chinese Oil Painting Masters, Shishi Chong [M]. Hubei Fine Arts Publishing House, 2002. (in Chinese)

[5] Case Studies of Famous Chinese Contemporary Oil Painting Masters: Liu Xiaodong [M]. Hubei Fine Arts Publishing House, 2000. (in Chinese)

[6] 150 Years of Modern Painting [M]. Guangxi Normal University Press, 2017. (in Chinese) 